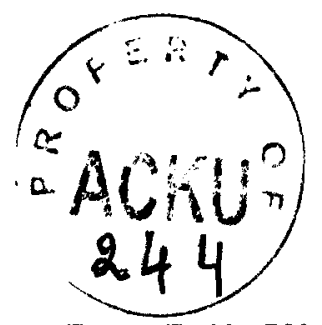

\title{
THE SOCIAL ASPECTS OF RECOVERY IN A FRAGMENTED SOCIETY
}

A Paper to be presented at the Seminar on the Potential for Recovery in Afghanistan and the Role of International

Assistance

$$
\text { Geneva, 5-7 May } 1989
$$

Nassim Jawad, Director, Austrian Relief Committee, Peshawar

\section{Background}

Afghanistan has always had two natural characteristics as a country and as a nation: the united nation and country against invaders from outside and the fragmented country and nation in peace time. Throughout the history of the country rulers always used the fragmentation as a means of political power but they always united the fragments when there was a danger from outside.

While the fragmentation was previously based on ethnic, linguistic and tribal differences, the religion had been of a minor difference in many cases. There were only two major religious sects, the Shites and the Sunnis, between whom there were conflicts even in the 505 and 605 but only where they were mixed in the same areas. This mixture of the two different religious sects was very limited, i.e. in Kabul, Kandahar and partly Herat but mainly in central Afghanistan, where Pushtoons were sent out to take over land and property from the Shiia Hazara tribes, the last time being in the 1880s. Neverthless in the last decades before the war and the Soviet invasion in 1979, many of these groups in different parts of the country started to accept each other on the basis of peaceful coexistence.

From my own experience in the late $50 s$ as a child when my family decided to move out of the Shiiaghetto in the centre of Kabul to another place outside the city where no Shiia family had tried to live before, it took us at least five years to be accepted by the community, but once accepted we never had any problem afterwards and I made my best friends within the same community.

The ethnic and tribal differences were still a major obstacle for the unification of the country. I still remember in the late bos if you asked an Afghan where he/she was from you never got the answer "Afghan", he/she would always name his/her tribe and the more educated would name the province.

Since the division was always used as a political instrument, no attempt has ever been made to change it to bring the different ethnic and tribal groups closer.

Because the history of the country was made and written by 
the Pashtoons and it was ruled by the Pashtoons almost throughout its history, a minority group of Pashtoons has been made a majority group and given the legitimate right to rule the country. (Official figures indicate $40 \%$ of the Afghan population is Pashtoon.) This resulted of course in more fragmentation of the Pashtoon tribes whereas it helped the minority groups who all together built the vast majority to stay together and be united.

As a result the minority groups (Hazaras, Turkomans, Uzbeks, Tajiks and so on) became rather powerful tribes among themselves whereas the Pashtoons continued to split into subtribes.

Also, due to the above facts the strongholds of the previous Governments were politically the Pashtoon tribal areas; despite less support among the other ethnic groups yet they practised more power. Whenever a tribe challenged the governments they were soon divided into smaller sub-tribes.

Although in Pakistan the government has no real power among the Pashtoon tribes because it does not have their support, yet it has been able to establish more contact, at least with certain parts of the tribal areas, and those who do want to benefit from the central government's facilities have to go into a trade-off and accept demands from the government. For example, those who wish to have ID cards or travel documents are automatically obliged to the rule of the central government. In Afghanistan, although the tribal areas have not been considered as such and there were no boundaries as such to divide the tribal and non-tribal areas officially, yet the government had less control. Within the major tribes the different sub-tribes never had any influence on another sub-tribe and so on.

The religion besides not being a major reason of fragmentation before the war had also a somewhat different status and value to the Afghans. If you asked an Afghan before the war about it, he would say first he was an Afghan before he became a Muslim. In other words, although Islam was the national religion and had a high value from the religious point of view, it was the traditional rules which determined the social and cultural rules and regulations.

The power was always divided among the powerful people according to the traditional system. The traditional power was structured differently in different parts of the country. For example, the Jirga was the only base of social, economic and political structure among the Pashtoon tribes along the Pakistani border but in the southwest it had less impact, for example in Kandahar, where the religious figures and big landowners had more influence. Among the tribes in the north and in central Afghanistan, there were always the wealthy 
people who ruled the tribes or used the shuras where there was a stronger influence of the religious scholars.

In a recent trip to Kandahar, discussing with a Kandahari commander about the roles of Shuras (or Jirgas) we asked him how someone could become a member of a Shura or Jirga or in other words represent a village or a Woluswali or a District. He said, "three kinds of people: The wealthy and powerful, the well-knowledged and those who are capable of achieving something "extraordinary."

Before the war the wealthy people gained their power not only through their wealth but also through distribution of their wealth, by feeding large numbers of people, supporting poorer farmers by ploughing their land with their oxen and/or tractors, by sharing the crop if there was a decrease in food production, and so on.

Those with knowledge were either educated through the formal education system or religious scholars who gained a lot of knowledge by studying and who certainly knew more about the world than any normal person in the village and could impress the villagers.

Examples of those with "extraordinary capabilities" emerged during the war. For example, someone who found out how to use a sophisticated arm or any other war machinery proved to his community that he was capable of doing extraordinary things which others cannot and so he became the commander and gained power.

I know a man, personally, who was our neighbour for years in Kabul. When he first came to Kabul he was illiterate. After he found a job he started to learn how to read and write. Since then he reads papers, magazines and books printed in Iran, Afghanistan and Pakistan and by reading regularly he comes across a lot of news and also information about happenings in the rest of the world, scientific issues, etc. He is now back in his village since the war started and is considered a professor who can talk about AIDS and nuclear disarmament. So, he is one of the most powerful people in his area although he is very poor.

To return to the fragmentation issue, during the war this was not only enlarged within the tribal system but also reinforced through religious fragmentation. Outside influences during the war split the society into different religious sects besides extending and enlarging the tribal and ethnic fragmentation.

The "Reforms" announced by the Kabul regime in the first years, without any grass roots support or preparation, were 
carried out by a handful of "intellectuals" and provided the opportunity for some religious leaders of the resistance to wipe out the role of the intellectuals during the war and to blame education for all that happened during the war. The intellectuals may also be ousted during the rehabilitation and reconstruction of Afghanistan, which will result in their having to remain in the host countries where they reside presently. As a result the reconstruction and rehabilitation process will become an immense problem for the international community without the participation of the limited number of the Afghan educated elite still available.

The longer the war continues, the more fragmentation there will be and the clearer the lines will be drawn between different political, tribal and religious groups and parties. The recent Council of the Afghan Mujahedin and the current Interim Government is a living example of the latest developments.

Nevertheless, the Afghans are capable of solving their national problems if they are left alone. Therefore, if we all wish Afghanistan to become a peaceful country again, we should let them solve their problems on their own without outside interference.

Also from the economic point of view, although Afghanistan was considered among the poorest nations of the world, it still managed for some time to be self-sufficient. Since it never became a colony there was also no interest from any side to help the country to develop; it stayed a "backward" country but it was self-sufficient.

If the tribal differences directed the country into fragmentation, they also provided them with high values, such as honor, pride and dignity, which led to their victory over a superpower, and those values still count and can be helpful during the reconstruction and repatriation if they are considered seriously.

Discrimination should be avoided and prevented between different ethnic groups and religious sects, between rurals and urbans and so on, which can occur by inequitable distribution of assistance; the social, political and cultural values must be respected; and finally, no distinction should be made between returnees, displaced persons and residents. Everyone has suffered in Afghanistan and every part of the above three groups had their advantages and disadvantages, but they all desire assistance equally. We want to help the whole of Afghanistan to rehabilitate and rebuild and not a part of it. 


\section{Returnees}

Returnees or presently refugees will have to be divided into different sectors but also the differences between the refugees in Iran and Pakistan have to be distinguished.

Approximately three million refugees are living in Pakistan, who mainly come from the southeastern part of the country. Up to $85 \%$ of them are farmers from the rural areas, approximately $10 \%$ are skilled personnel divided between approximately $10 \%$ are skilion of the rural and urban areas, and then
traditional skills of
probably $5 \%$ are urban refugees from towns and cities.

The urban refugees have mainly settled themselves in the cities and are involved either in work with various refugee agencies or with those who are involved in work cross border. Many of them are residing temporarily and are waiting to get out of Pakistan and $g o$ to the West, of whom a small minority out of Pakistan and go to the a settlement but the majority
may return voluntarily after a considering the size of
might be reluctant to return cong destruction and the political situation.

The 10\% skilled refugees are probably better off than the other two groups since they are able to practise their occupation and earn their own living without being dependent on handouts of the international relief community. A number of income generation schemes by Volags and the UN agencies have been of great support to these people. Besides, a number of vocational training projects have added to the number of skilled refugees who will be a great asset to the country during the rehabilitation process.

The majority of the refugee population in Pakistan, the $85 \%$ farmers from the rural areas, are the most affected ones since they have had no access to land and therefore could not practise their occupations in agricultural and animal husbandry work, they had to rely on rations and handouts provided by the aid community. Although some of them have been involved in the local economy and agriculture as unskilled labourers and/or small traders, i.e. selling fruit, vegetables, etc. in bazaars, their number is considered rather small compared to the total number of the population. Therefore there has been a great deal of dependency created among them, which will make it difficult for them to get back to normal i ife after ten years of reliance on handouts.

Socially and psychologically the women have suffered the most. While the male population is able to move outside their compounds and/or to do some jobs, the women are restricted to their compounds. The women have been involved in agriculture and animal husbandry in all parts of 
Afghanistan. The villages at home provided a lot of opportunity to the female population for social and cultural activities. Besides their initial work of agriculture and animal husbandry, they also were involved in handicrafts, which is very limited within the refugee camps. All these facilities do not exist or are very limited in the refugee villages.

Statistics from the health clinics where facilities for women exist indicate that the number of women attending the clinics is much higher than the number of male patients. Surveys and statistics throughout the last ten years indicate that approximately $65 \%$ of the female patients attending the health clinics are not physically ill, they mostly suffer from mental and chronic diseases, but the majority of them use the clinics as a social and communication centre. There are more births in the camps compared not only to the villages in Afghanistan but also to the past history of the same families.

Only 10-15\% of school age children can attend some sort of school in the refugee camps, which are mostly a mixture of primary schools and madrassas. Many refugee children, particularly urban, attend Pakistani private or government schools and get used to Pakistani language, culture, history and so on and have little or no chance and opportunity to learn their own language and history. I have wittnessed many families whose children speak better Urdu and English than Farsi and Pashtu. Very few girls have had access to education.

In general there have been a number of changes taking place within the refugee community at all levels. The urban refugees have been under considerable political and religious pressure and have had to accept a lot of social changes, to their disadvantage, while living in Pakistan. The rural refugees have become acquainted with some sort of urban life through freedom of movement and their lack of access to land and their involvement in urban trades and activities.

The urban refugees, again particularly the females, have suffered a lot from the social and cultural pressure, e.g. very few educated Afghan women living in Pakistan are able and/or allowed to work and practise their occupation. This was one of the reasons, besides the political tension, for migration of a large number of educated people to the West.

Although the refugee camps and the war in general brought many tribes and ethnic groups closer to each other, it also brought a lot of pressure on them to avoid any criticism by their neighbours caused by the density of the camps, i.e. the large number of people living in a small place. 
When they return to their home localities the refugees will face different social and political pressure and difficulties. They might be discriminated against by those who stayed back at home because they fled the country, and they might bring many changes with them from the host country.

Reclaiming of land and property may cause problems in some areas, particularly for those who came from far distances and had no access back to their land and property during the war. This may not be of a major problem for those who came from the areas close to the border since most of them used to go back to their villages, as far as possible, and cultivate their land so they had some additional income while living in the camps. Others have either rented or handed over their land temporarily to their fellow villagers, with specific agreements to make sure they do reclaim them when going back home.

Those involved in the local market in Pakistan will be very reluctant to return back and will be the last to go if the international aid does not provide sufficient access and participation to them in the local market in Afghanistan. While the residents in Afghanistan have established strong connections with the local commanders, of whom not necessarily all follow the line of the political parties in Pakistan, the refugees have been more tightly associated to the political parties as a source of access to rations and other benefits.

While the population remaining inside was not affected too much by the various new religious sects and have rather dealt with each other in many areas on the basis of peaceful coexistence, new religious sects have been introduced to the refugee community and the division is greater than in Afghanistan itself.

As mentioned before, many rural refugees are now urbanised and might be reluctant to go back to their village but rather stay in towns and cities, especially if they are attracted by aid and relief assistance. If the number is large, the impact will seriously affect the country, particularly considering the level of destruction in the rural areas, i.e. houses, agricultural land, animals, infrastructure, etc.

All these differences on political, social, cultural, economic and religious issues will cause further fragmentation of the society if special care and attention is not paid.

A major problem seems to be the refugees in Iran. Since there 
was almost no international or any major national assistance program for them in Iran, they had to integrate themselves within the Iranian society and community economically, socially and culturally. Many refugees now working in Iran may have established a better life than they had in Afghanisatn, at least from the economic point of $v i e w$. Reports from Iran indicate that not many refugees will be willing to return back home unless they are sure they will be able to continue their occupation, trade or any other business they might be involved in in their host country. Specially since there are a larger number of educated people living in Iran, this will affect the rehabilitation process, again, with lack of educated and skilled personnel who may not be willing to give up their higher living standard so easily.

\section{Rural Exodus}

The rural exodus started already during the war and can be divided into three groups:

Those who migrated to cities and towns due to pressure of war but mostly because of economic reasons within Afghanistan. Kabul is a living example of this exodus: a city with approximately 700,000 population in 1978 is now accommodating over 2 million people.

- Those who fled to Pakistan and are acquainted now with life in towns and cities, even if they lived in refugee camps. Here, as mentioned before, while the majority of the male population had access to the urban areas and have adopted a certain urban attitude, the women have little or no access to the cities and have been confined to their tents and compounds, which could result in the male population deciding to go back to the rural araeas if every needed assistance is provided -- but there is a danger of them trying to stay in cities and towns.

- And finally, the majority of refugees in Iran who are now living as urban refugees and are fully equipped with the urban standard of living will be very reluctant to return to their villages -- if they return at all.

Most of these people may be tempted to stay in the urban areas especially if they are attracted by aid and foreign assistance. Once this trend has started it will then be very difficult to stop it, because as soon as some agencies start to take care of maybe even a limited number, they will attract the rest of the rural population also to migrate to the cities and towns in order to get some assistance.

As a result a mass of poor urban citizens will be created, 
which will then end in a disaster. Examples of such migrations in Asia as well as in Africa have proven to be the cause of economic disasters.

One of the main problems which could lead to such a mass migration and increase in urban poor will be lack of manpower. During the war an estimated one million people have died, the majority of whom were young men, another estimated 2-300,000 have been disabled, who will need special care and will not be able to be of any use during the reconstruction period. However, through special attention and specially designed programmes they can be helped to become at least independent and able to help themselves.

Many people of the younger generation who have been living in refugee camps for years are no more familiar with their rural lives and have become parasites unless they were involved directly in the war activities. Those who were actively involved in the war for the past ten years know nothing other than war and their only knowledge is how to clean, maintain, carry and use their Kalashnikovs.

Many of them started to fight when they were 10 and 15 and are now 20 and 25 years old. If you ask them how much seed is needed for one jerib of land they will not be able to answer the question. In surveys about agriculture recently carried out inside Afghanistan but also in refugee camps in Pakistan, the only sources of information have been the older generation. To reintegrate this young generation back into the society will be the most difficult task of the rehabilition process.

Any attempt by aid agencies to bring in big changes, e.g. to replace manpower through mechanisation in a short term, will fail due to lack of maintenance, trained personnel, spare parts, access to fuel etc.

Tribal. Ethnic and Reliqious Dimensions of the Recovery Process

Throughout the history of Afghanistan the tribal system has been the sole social, political and economic structure, all over the country but particularly among the Pashtoon tribes. All local, sometimes national and in one case even international issues (after the Second World War with thousands of German nationals in Kabul) have been discussed and decisions achieved through the councils (SHURA or JIRGA). Although the decisions have seldom been written down they have been accepted and no one could escape them. Anyone attempting to escape a decision or break the law would have to leave his community and would not be able to survive in the same community. All decisions have been witnessed by the 
entire community and everyone was aware of the decisions.

In many parts of the country, particularly in the areas close to the border where political parties have had more influence, this traditional structure has lost its values. Where it still exists, it has been politicized. Political values have gained more influence in some areas and have replaced the tribal values.

Ethnic disputes from pre war have become now political disputes.

For example, a village dispute before the war divided the villages, whereas the political disputes now have divided the families. During my trips in Afghanistan over the past ten years I often witnessed families whose male population are totally divided among themselves. There are families with, say, five male members, four of them might belong to four different political parties where the fifth might as well be a Militia or otherwise supporter of the regime.

If the war on the one hand forced different ethnic groups to come together and join hands, the best example is central Afghanistan, where Hazaras and Pashtoons, Sunnis and Shiites, Farsi speakers and Pashtoo speakers and so on live, fight and suffer together and also take care of their socio-economic issues together. On the other hand, through the political and religious impact the danger of further fragmentation increased in other areas. I remember in 1970 when I travelled in southwest Afghanistan I came across many villages and small towns where not everyone knew who the King was and what Kabul meant, whereas today Hazaras and Pashtoons passing through each other's areas know more about each other -- but at the same time they have become more political. If the traditional values are not restored and reestablished, any assistance on a political party base will fail.

At the same level as the political values the emphasis on religion is today much stronger but also more fragmented than before the war. Religion was the main motivation for the Afghan nation for continuation of the war and their successful victory. At the same time its strength and its political values have drawn clearer lines between the communities.

An example of the religious fragmentation is the recent development in the Kunar Valley after the Mujahedin took over power. The cause can be clearly seen in the foreign interference of the Afghan conflict.

All these differences are not only resulting in the fragmentation of the rural population but also bring a lot of restrictions for the urban population. In the latter case 
the women and children again suffer the most: social restriction, changes in their attitude towards cultural habits and most importantly in the education sector, i.e. in Kabul, Herat and other major cities.

\section{Education and Training}

Due to the war a whole generation has been deprived of education.

In Pakistan and Iran only 15-20\% of the school age children have access to some sort of education while the rest spend their time around the camps or towns until they are capable of doing some work and at the age of 10-12 they already start working to earn some money and help their families with some additional income. Child abuse did not only take place at work, they have also been used and abused for political purposes. The majority of children have been victimized for political propaganda. Children in refugee camps in addition to political and religious aspects of propaganda have also had only limited access to education, i.e. primary school, and have been acquainted with the Pakistani history, culture and language. The same situation applies to those in Iran: by attending Iranian schools since there was no special education program for them. Then there are children who had to adopt the western education plus cultural, linguistic and other aspects. Children in major towns, e.g. Kabul, have been trained under a Sovietized system, in addition thousands of youths and children were taken to the Soviet Union and are still there.

And finally, the remaining tens of thousands of children mostly in the rural areas have grown up with war and have become young warriors. In a recent trip in Kandahar and Logar, when asked what would they like to become later, one out of 20 children said farmer or teacher, the rest wanted to become Mujaheds. The children asked in these informal interviews were aged between 6 and 15 whereas the ones of 15 and over had already been recruited as Mujahids.

These children make up the next generation of Afghanistan on whom the nation has to rely for the future process of reconstruction and rehabilitation.

Considering the fact that there was a literacy rate of approximately $10 \%$ in Afghanistan before the war, the number of trained and skilled personnel has been rather limited. But even then many have been killed, imprisoned or fled the country into the neighbouring countries and the higher educated went farther on to the west, of whom not more than 10\% will come back to Afghanistan. 
Lack of trained personnel will certainly push the international aid community to employ expatriate staff, especially those agencies with more ambition and hopes to rebuild the country in a quick and fast operation. They might be of more danger than help to the country's future in the long term and may make mistakes in the process, due to lack of understanding of the Afghan reality, which could bring Afghanistan into a long-term dependency. We already face shortage of trained Afghan personnel within the small scale of the NGO operations inside Afghanistan and agencies already compete with each other to get the few available best trained staff at any cost.

\section{Conc lusion}

Ten years of war and rootlessness in exile have pushed the Afghan nation backwards for many decades and have resulted in a number of social, political, economic and cultural changes. It has made a complex situation more complicated and a fragmented society more fragmented.

1. Ethnic and tribal differences have been reinforced by religious and political differences.

2. The displacement of approximately $7 \mathrm{million}$ people has resulted in economic dependency through lack of ability and availability of land and facilities to practise their skills and occupations.

The dependency syndrome is seen more clearly among the refugees in Pakistan than the others. A friend who wrote a paper recently on involvement of women in income-generation schemes and their role and that of their children in the reconstruction process, describes the fate of the refugees with a true story from a classroom in a refugee camp in Pakistan:

"The classroom was full of young Afghan boys armed with colored pencils and empty sheets of paper. They were told to draw pictures about their future, so from their memories and dreams they began to depict the scenes they imagined. The expected images were revealed - airplane pilots, helicopter gunship pilots, mujahedin with big guns, etc.

"However, in the pile of papers, one had an image that was distinctly different than the others. It was a picture of bright flowers, some trees and a green garden. When the teacher began to talk and look through the pictures with children he discovered that amid this room full of future 
fighters and mujahids and pilots there was only one who would like to be a gardener, the question was asked: "How will you eat then and where will you get your food ?" The answer came back: "We have our rations!" "

3. Millions of people have been deprived of their basic rights to live in their own environments, which has caused an immense psychological effect on the population. Among them women and children have suffered the most. In order to safeguard the honor of the women, more restriction has been put upon them as a means of protection. A whole generation has been deprived of the right to education.

4. Rural populations have become somehow urbanized and urbans had to give up a lot of advantages which they enjoyed in the cities and accept restrictions enforced by the war, economically, socially and otherwise.

5. The future generation has been imposed with strange cultures and social life in the host countries and has adopted others cultures, languages and social aspects which they will carry with them when they repatriate. This is another cause for further fragmentation in the future.

6. Ethnic and tribal values have been replaced with religious and political values.

7. Yet a lot of positive changes have also taken place which together with the rehabilitation of the social and cultural structures are potential for a smooth rehabilitation and reconstruction process:

a. Through the war different ethnic and tribal groups have come together and have learned how to live beside each other on the basis of peaceful coexistence.

b. In order to safeguard their social values, i.e. honor, dignity and pride, both refugees and residents have helped each other more than they would have before the war. For instance, beggary and prostitution which are common in other parts of the world in similar situations are non-existing among the refugees nor in Afghanistan.

c. By fleeing their home villages, particularly refugees in Iran and Pakistan have been forced to live with the different ethnic groups and tribes 
from their own country they also had to face the outside world and accept and respect the values of the development of their host countries and start to understand openness towards life style different to their own -- some have even adopted these styles.

d. In the refugee camps and in towns and cities outside their villages many of them had the privilege of certain facilities such as medical care, education even if limited and access to infrastructure which they will miss when returning back to their home villages. This can become a potential for demanding social services even if they have to be operated in the community's own way.

e. If they learned a lot through living with other people and strangers, they also learned how to take advantage of the aid from the international community without allowing them to interfere in their lives. This should have given a good lesson to the international community to avoid any interference or radical changes in their lives and to be rather cautious to help the Afghans according to their wishes.

f. The limited number of refugees who managed to establish themselves in their host countries and even acquired new skills and became self sufficient has proved that they are hard working and have the potential to help themselves to rehabilitate and reconstruct their war-torn country if they are given the chance and are left alone.

9. Finally, any attempt to bring about radical changes in the economic and/or social aspects of their lives during the repatriation will fail. We all have to keep in mind that Afghanistan today is maybe back in the 30 s and $40 s$ and we have to be patient for the development of the country. Two Afghan proverbs describe it very nicely: "Patience is bitter but has sweet fruits" and "hurry is the work of the devil".

\section{Recommendations}

If we are all here to help the Afghans then the most important thing we always have to keep in mind is to "Help Afghans to Help Themselves"! 
By doing so we will assure the Afghans of our good will and preparedness to help them for the rehabilitation and reconstruction of their country, that is to involve the Afghans not only during the implementation of the reconstruction plans but already during the planning process. Any plans made without the active involvement of the Afghans themselves may be hampered during the implementation.

When I ask my colleagues in Peshawar or elsewhere why they don't involve their Afghan colleagues more, I always get the same answer: "There are no Afghans," which is not true. What they mean is that there are no Afghans who can understand them and work according to their plans and wishes. So, we forget, most of the time, for whom we work. Very often we talk about Afghan projects but in reality they are our projects and our projections for the future of the Afghans. We most of the time see the future perspectives of the Afghans from our own narrow window. Maybe because some of us have been frustrated by our own communities and societies by not being able to achieve what we wished and so we hope to achieve them at least in a different society and with different poeple.

Our norms and beliefs and understanding for relief and development are different than those of the Afghans. Some of us may have gained a lot of useful and extensive experiences from other developing countries but they may not necessarily apply to that of the Afghans.

Time and pressure for success is a major problem for many of us. A lot of agencies are bound to prove to their headquarters and donor agencies immediate success in order to be able to carry out further work. Time though so costly for us has none or less value for the Afghans, even in their own lives.

Political differences and solutions should be entirely left to the Afghans themselves without any interference from outside. The Afghan society at this stage is not only fragmented but also very fragile and sensitive. Traditional tribal and ethnic values of the past which have been the main structure for socio-economic matters can and should be restored for the reconstruction process. By utilizing these values we can avoid politicization of the reconstruction process.

A major problem we will all be facing is the lack of qualified and trained Afghans for the implementation of the reconstruction and rehabilitation programmes. Therefore all of us, UN agencies, NGOs, bilateral and other specialised organisations, should immediately start massive and large 
scale training programmes. This should be encouraged even if a high number of expatriates may have to be involved in the training programmes. It is better to involve the expats today to train the Afghans to carry out the work later instead of having a large number of expats to carry out projects in Afghanistan later on.

A large number of highly educated and qualified Afghans are presently residing in the West, Europe, USA, Australia and Canada. Many of them are reluctant to return back because of the political instability. If they were provided social and political protection by international agencies they may be willing to return back, at least at the stage of the preparation and training in Pakistan. UN agencies can play an important role in this regard.

A major obstacle among the international community presently working is the lack of specialized personnel. Very often, specially NGOs, because they cannot afford to hire qualified staff rely on rather young and inexperienced volunteers who not only do not understand the Afghan society but also have no professional background in the field in which they are supposed to work. This might be counted as a major reason for failure of development activities in many developing countries around the world.

The UN agencies, bilateral and other multilateral agencies should bring in professionals in different fields, i.e. those who have long years of experience in movement of people, goods and commodities and reconstruction programmes. NGOs should be supported not only with funds for their programmes but also for other costs such as hiring professionals. We have to keep in mind that the capacity of the NGO community is very limited and can be expanded only if their managerial capacity is expanded.

Education is and will be the most sensitive field for recovery and the future plans. Attempts of localised or individual agency systems for education should be avoided because it can create further fragmentation of the different parts of the country. Therefore the leading UN agencies, UNICEF and UNESCO should rather work on a nationalized educational system. We must also keep in mind that Afghanistan today is a more rural society than it was ten years ago and will need more integrated programmes for the rural areas particularly in the education field. Primary education is certainly a priority for the rural areas but the first step will have to be ensuring sufficient numbers of teachers with good qualification. This will mean massive teacher training programmes to prepare for a national educational system. 
Any educational system should be integrated according to the needs in the rural areas, i.e. agriculture, animal husbandry, health, etc. and should be designed by the Afghans themselves; expats and foreign agencies should provide financial support and technical advice such as teacher training.

The majority of girls and women have been excluded from any educational system in the past ten years. Therefore more emphasis should be put on them. One way will be informal education, e.g. health centers and other public centers can be used for the purpose where women have free access. A number of NGOs have a number of successful projects in this field while working with the refugees in camps in Pakistan. I suggest the international community do a study of the available projects in the refugee camps and draw recommendations and guidelines for future work in Afghanistan.

Vocational training with literacy campaign will enable the rural poor to become an active part of their society. Again a number of agencies have been working on a series of basic and advanced training courses in different fields in the refugee camps and the international community may carry a separate investigation and study of available activities for future work.

Free food distribution will certainly attract large numbers of rural and poor urban into cities and towns even if it is on a short term base. Therefore food/cash for work projects should be carried out instead which will firstly help the rural population to rebuild their houses and fields but also lessen the danger of economic dependence, provided they are carried out in the villages and rural areas and have their bases there and not in towns and cities.

In general any aid should be provided on the village base in the rural areas even if it might be costly, because otherwise in the long term free food distribution might be much easier and cost effective but will be very expensive and may cost the future of the country.

Income generation projects on village level for landless, skilled and women should be created to basically cover their own needs in the villages for the first phase of the recovery; they can then become involved in marketing outside their villages at a later stage. Again there are agencies who have gained lots of experience in the refugee camps and can be useful for broader programmes during the recovery process.

Special attention should be paid to women and in particular the widows with their available traditional skills, 
handicrafts, carpet and kelim weaving, home skills, kitchen gardening, small tree and animal nurseries. All these activities have been experienced by NGOs and some international agencies with the refugees and many have shown extensive success. But again an extensive research will be nepded to identify the needs and the possibilities of such programmes.

Mechanisation of agriculture and other economic sectors in large scales should be avoided and be carried out with very small steps. Afghanistan is not ready for such large scales and will have to be taken step by step into mechanisation because of lack of trained manpower, infrastructure and other facilities.

Local traders and markets should be used for all food and commodity distribution. This will first help the national economy and secondly requires less administrative infrastructure. And since there will have to be a large number of expats involved in administration, it will also be cost effective.

In order to achieve all these goals there is an immense need for the reconstruction and new construction of the country's infrastructure, particularly roads and access to the rural areas, before anything else, especially in the remote areas. This will be of benefit for smooth implementation of large scale programmes and will also provide access to the rural population to the cities and towns for transport of goods and other things they may need from the cities and towns. In other words, as long as there is sufficient access between the rural and the urban areas and sufficient work for the rurals to have enough income and be able to purchase goods not available in their areas, much of the rural exodus can be avoided.

Finally, we are all puzzling at the moment whom in the country to use as partners for the implementation of our activities and plans. There are different opinions and practices, i.e. Shuras, Jirgas, local commanders, combination of both, Maliks, other influential personalities, Government, etc. In my opinion, whatever system and whichever instance we may be using will make us and our programmes to a certain degree dependent on those seen as our partners. For us it is important how much that person, those persons and/or institutions will benefit from the work we carry out with their cooperation.

Therefore ideally a central government with sufficient influence all over the country will be the best answer. But sad as it is, this is not the reality of Afghanistan. At the moment there are neither local governments nor a central 